\title{
On the Application of "Thirteen Rhymes" in National Singing Teaching
}

\author{
Jing Zhou ${ }^{1}$, Shuqing Lin ${ }^{2}$ \\ 1,2Hubei Engineering University, Xiaogan, Hubei, 432000, China
}

Keywords: thirteen rhymes; language; national style; singing skills

\begin{abstract}
Language is the basis of singing and it is an important means to express the content and emotion of songs. However, there are great differences in the pronunciation, rhyme, and tone between dialects and Mandarin in various parts of China. Reading quasi-character pronunciation, singing lyrics, and highlighting the local characteristics of language speech have become an important feature of the national style of singing. Therefore, if there are no clear words and phrases in singing, even with superb singing skills, it is difficult to express the unique ethnic style and national charm in the songs. The role played by the thirteen chants in the vocalization of singing is of utmost importance. It is one of the important means for the national vocal music training in China. It can also be mastered by singers with regard to the rhyme and the radio of the pronunciation.
\end{abstract}

\section{Introduction}

Singing is an art form that integrates music and language organically. It is an important way for humans to exchange information and express emotions. In real life, the languages spoken by people of different nationalities have their own characteristics. Language is the basis of singing. To demonstrate the national charm of this song, we have to associate it with the "Thirteen Kingdoms". Through the collection of data and documents over the past decade, we can see that the study of the national style of the "Thirteen Kingdoms" and singing is mainly based on the thirteen-pointed words and phrases, the aesthetic orientation of the national style, and the national charm of singing skills.

\section{Outline of Thirteen Rhymes}

\subsection{Concept of Thirteen Rhymes}

The original meaning of " $z e$ ” is: track marks, traces of wheels running through. The word " $z e$ " is used in the rhyme of poetry, songs, and verses. It can be used in the rhyming and rhythm of opera.

The thirteen rhymes generally refers to the 13 rhymes that use Beijing Speech as the standard sound in the northern art of rap, and use the same or similar basic principle of rhyme. Inductive classification. It is concise and easy to remember, sings freely, wide in rhyme, easy to use, and more musically pleasing. Therefore, in the application of singing, the 13-year-old can be completely used in the creation of music aesthetics, including rhyme parts such as poetry, words, songs, and poems.

\subsection{The Number of Rhymes}

For the sake of easy remembering, the number of strokes of the thirteen verses can be made into a form of seven-character poems that are easy to remember.

\section{Fahua poetry}

By Yi Rong

Huai lai you qiu yi hui dui

Yi qi nie xia gu su bei

Ren cheng yan qian po miao wu

Zhong dong jiang yang yao tiao fei

A poem contains 13 rhymes: 
1) Fahua rhyme: Finals include a, ua, ia.

2) Suobo rhyme: Finals include e, o, uo.

3) Huailai rhyme: Finals include ai, uai.

4) Youqiu rhyme: Finals include ou, iou (iu).

5) Huidui rhyme: Finals include ei、uei（ui）。

6) Yiqi rhyme: Finals include I, ü, er.

7) Niexia rhyme: Finals include ê, ie, üe.

8) Gusu rhyme: Finals is u.

9) Rencheng rhyme: Finals include en, in, uen（un ）, ün.

10) Yanqian rhyme: Finals include an, ian, uan, üan.

11) Zhongdong rhyme: Finals include eng, ing, ueng (weng ), ong, iong.

12) Jiangyang rhyme: Finals include ang, iang, uang.

13) Yaotiao rhyme: Finals include ao, iao.

Note: In fact, there is another one included in Yiqi rhyme.

\section{Application of Thirteen Rhymes}

\subsection{The Relationship of "Thirteen Rhymes" and Vocal Music}

Thirteen rhymes are the 13 rhymes used in the lyrics of Northern operas. The relationship between them and vocal music is closely linked. From ancient times to the present, the expressions of poetry, words, songs, and poems in our country are all created in the form of rhyming rhyme. This is not only conducive to expression of affection, description of the scene, but also conducive to the creation of works to a greater extent, with exquisite and perfect artistic effects, including rhyme and rhyme (rhyme rhyme is also one of the ways of rhyme). There are Taoist, Song, Yuan, and Ming-Qing fictions. There are strict rhymes in them (poetry is called rhyme and opera is called ze). Therefore, different versions of songs can be sung as lyrics. Such as: "Water melody" There are two versions of Tang Lijun and Yu Shuzheng singing). With the changes of the times, the development of singing has continued to change, but the strict rhyme that is based on lyrics and singing has always existed. As a rhyme system for lyricists singing in Northern operas and folk arts, the thirteen verses are indispensable for poetry, lyrics and composing, and rhyming together is a means of enhancing artistic effects from the aspect of rhyme. The 13-year-old was originally used by Northern Opera and Quyi. With the research and development of singing, its relationship with vocal music has become more and more closely. Nowadays, we have used the method of staggered use and combination of phonology, techniques, and singing in vocal music. "Thirteen miles" was conducted. The singing characteristics of vocal music and the combination of language and rhythm training can better explain the national style, singing skills and pronunciation of vocal music.

\subsection{The Relationship of "Thirteen Rhymes" and Singing Skills}

With the continuous development of the level of singing, singing is not only one of the ways in which people express and communicate emotions, but also one of the ways to cultivate a noble moral sentiment. In the process of continuously pursuing a more "tall" artistic realm, the singer must have a certain degree of research and mastery of the singing's norms, skills, and skills. When it comes to singing music, it takes more control over singing skills than talent. Talented people may not be able to sing well, but those who have both skill and hard work will surely sing well. This is beyond doubt. From this, it can be seen that when a singer sings, in addition to the good conditions inherent in the interpretation of the songs, he must also master the singing skills. Therefore, in terms of skill training, we can still start with the "Thirteen Points". Singing is based on language and it is inextricably linked with language. Apart from research on the expression of singing arts and the method of pronunciation, we also need to explore how to strengthen the singing techniques when combining 13 rhymes with singing so that we can make the singers have their stories when singing songs. The plot, style, and performance are even better. The feelings conveyed to the audience are more real. 


\section{The Case Study of "Thirteen Rhymes" and Singing Language}

\subsection{The combination of "thirteen rhymes" and "national singing method"}

The national singing of China is determined by various factors such as the geographical environment, history and culture, humanistic customs, national languages, and aesthetic concepts of the various ethnic groups, creating and developing an artistic singing method. When singing, if you can accurately grasp the words and phrases in the language, you can express the content of the singing more distinctive personality and ethnic characteristics, emotional processing is also more vivid image. The national vocal music in our country is unique. Apart from its distinct features in language, there is also a strict requirement between enthusiasm and lingering charm. When singing, it is necessary to have a "character", with a particular emphasis on the wording and voicing, with rhyming rhyme and sensation as a criterion. We should give full play to the singing art of our country's distinctive ethnic characteristics, and these are inseparable from the "Thirteen Stars" theory. For example, "Singing and Spelling Training and Thirteen Characters" edited by Mr. Song Chengxian (Beijing: Central University for Nationalities Press, 1998) and "The National Vocal Music Singing Art" written by Mr. Li Xiaozhao (Hunan: Hunan Literature and Art Publishing House, 2001 In the two books, they elaborated on the use and role of the thirteen verses in singing. Fully demonstrated the value of the combination of "Thirteen Kingdoms" and "national singing". E.g:

Sample 1 "Youth Dance" (Uyghur folk songs, adapted by Wang Luobin)

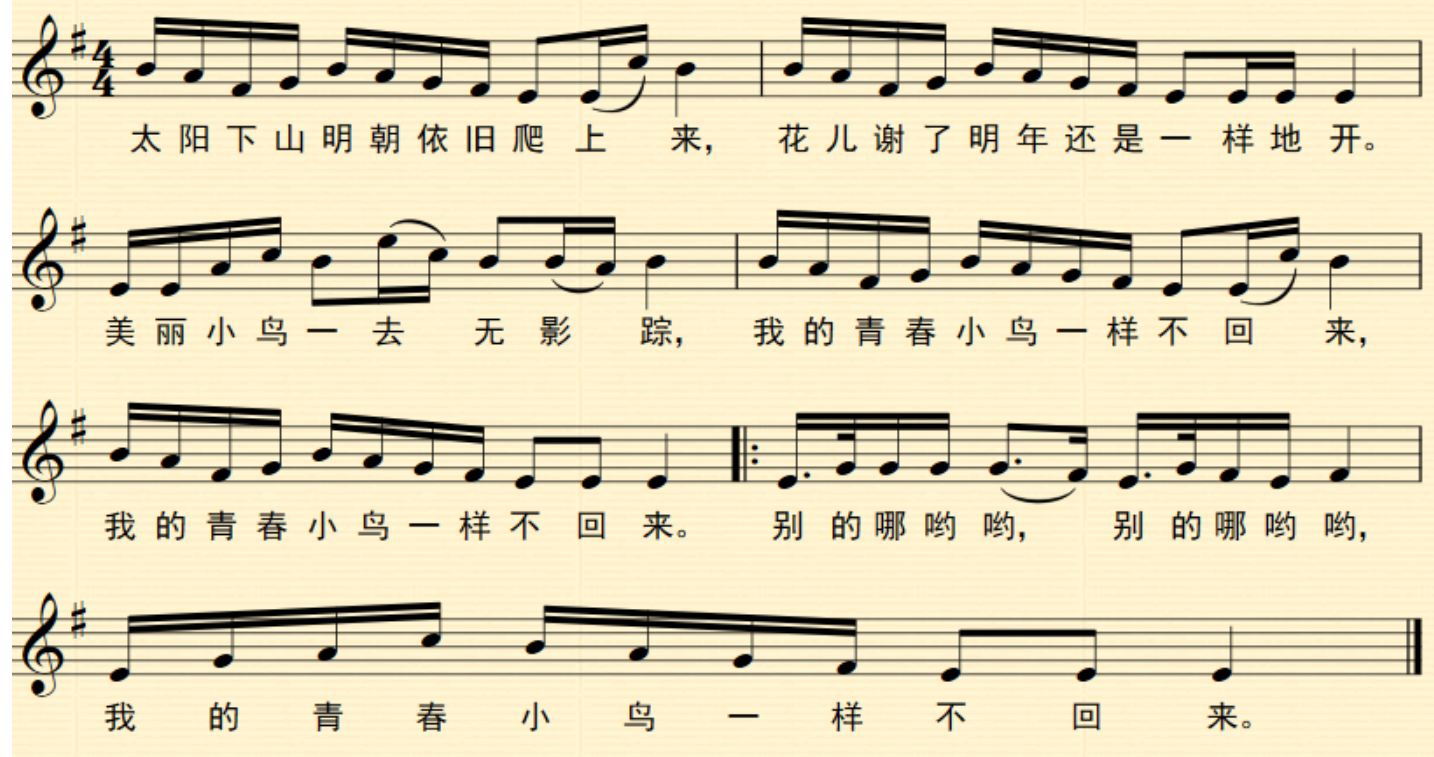

This Uygur folk song has the characteristics of "fish bite tail", and the arrangement of tune and the writing of Chinese classical poetry also have the same purpose. In all seven lyrics, there are four sentences that are basically the same melody. The lyrics "The sun goes down and the Ming dynasty still climbs up and the flowers thank next year are still the same.” The last lai of the previous lyrics and the last kai of the latter lyrics all have the same rhyme feet (ai) and belong to Huailai: The vowels include ai and uai, which also make it possible to achieve a consistent solution to the rhyme.

In the singing process of Chinese national vocal music, besides paying attention to biting words, we also pay attention to the rhyme collection that is bound to be involved in the rhyme. In Pinyin, all the word sounds are composed of initials and finals. In other words, most of the words are composed of rhyme, rhyme and rhyme. Therefore, returning to rhyme is also a feature of the national identity in national singing. E.g:

Spectrum Sample 2 "The Breeze of the Sea Breeze” - Selection of Opera "Red Coral” 


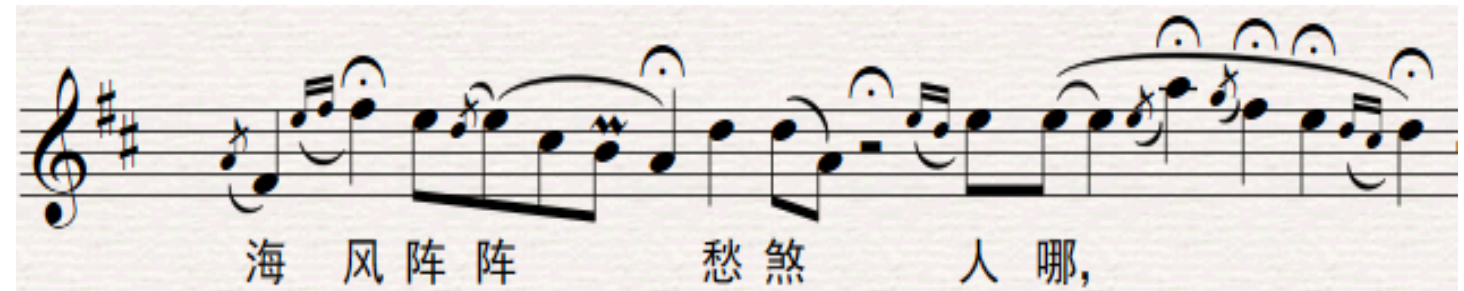

As shown in Table 2, the "rhyme" vowel is "eng” and belongs to "the Middle East". If the singer only bites the rhyme when singing, but ignores the rhyme and rhyme of the rhyme and rhyme, he will sing "eng" into the "ong” that belongs to the "Middle East Cong” vowel. Caused inaccuracy and lack of flavor when singing. In order to solve such problems, first, use the sound training of the "Middle East" to solve the problem of rapid sound change; second, keep the breathing and throat in line with each other; and third, keep the correct mouth shape, "eng "It is not the same as the "ong" mouth shape. After solving these problems, singing songs again will reveal significant improvements in the wording and spit, and the national charm.

\subsection{The charm of "thirteen rhymes" and national vocal music}

"Music flavor" refers to subtle flavors and interesting flavors. In ancient China, music and poetry were traditional aesthetic summaries. "Rhyme" is intended to mean the sound of harmony, also refers to grace, temperament, and taste. It is the aesthetic characteristics associated with music associated with hearing, extending to the rhyme in poetry; the commonly used vocabularies of taste are: taste, taste, smell, and so on. As a concept associated with feeling and taste, it has become an important category of aesthetic taste after various modifications and conversions. In our country's traditional music aesthetics, the combination of "rhyme" and "taste" embodies an important aesthetic feature of vocal music. The "moist flavor" in the national vocal music works in China includes rich and colorful concepts such as rhyming rhyme, being full of characters, and being diverse in style.

When you want to sing in vocal music, you can express the charm of the song most vividly. We can use "Thirteen Stars" training to "get rid of the rough". The 13-year-old was originally developed from the rhyme rhyme of Chinese ancient operas, poetry and rhythms, and was written by Mr. Ma Zhikai, a book entitled "The Thirteen Chinese Rhyme Dictionary" (published by China Drama Publishing House). We can also understand The relationship between the thirteenth and the opera. In the opera, the role played by the thirteen crickets made the rhythm of the opera more extreme, and the national vocal music in our country evolved from the development of the opera. With the clever use of national vocal music and thirteen gongs, the "moist lingering taste" of national vocal music has been better interpreted, and the personality and national characteristics of the national singing style have also been better released. E.g:

Case 3 "The woman in the mountains shouts the sun" (Gan Maohua, Wang Yuanping)

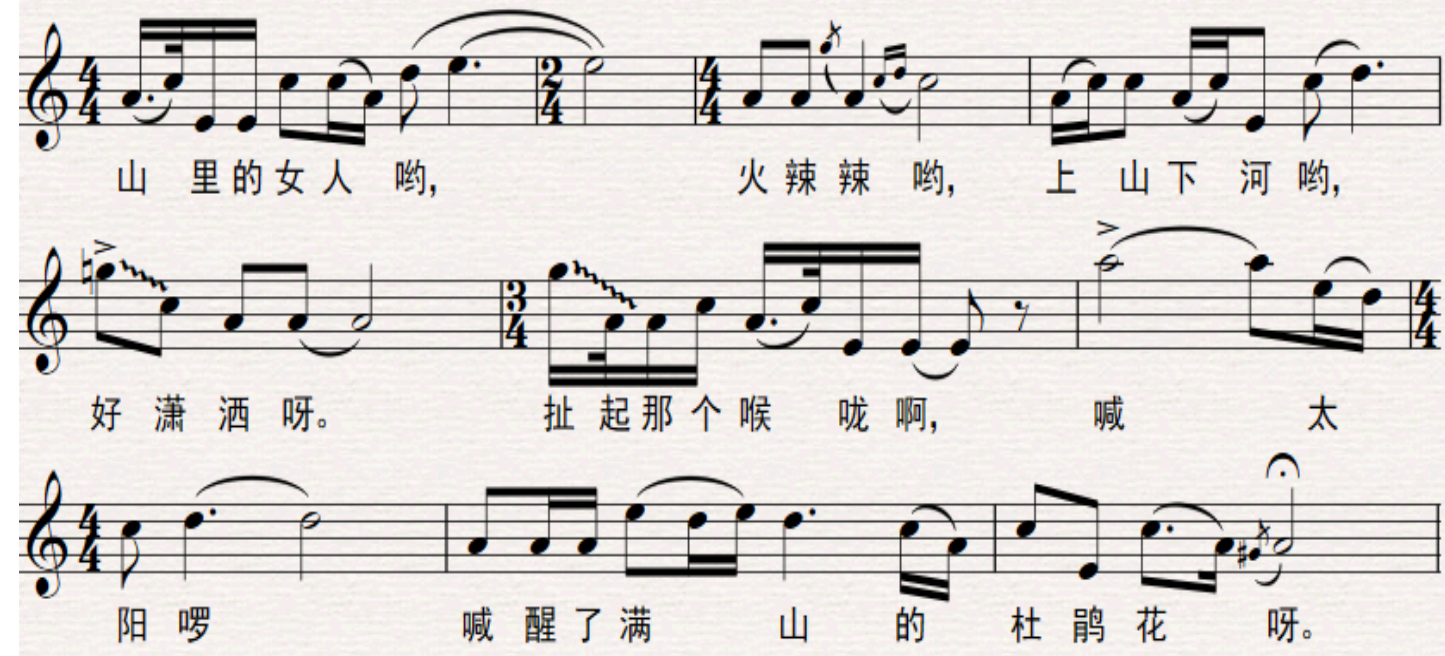


"Woman in the Mountains Calls the Sun" This is a song written in ethnic style in western Hubei. It reflects the desire of Tujia women to love life and yearn for a better future. Many of the lyrics of this song are reflected in the training of "flower buds", and "spirit", "sprinkle", and "flower" fall on the "a" sound. At the same time singing the song, boldly used the local dialect, but also pay attention to the sound of the state of science, language and tone characteristics combined. It fully embodies the song's national charm, ethnic style and local characteristics.

In addition, in order to display the national rhyme and taste of national vocal music more perfect in national style and local characteristics, attention should also be paid to the changes in rhythm, the contrast of emotions, the conversion of speed, and in particular the application and processing of decorative sounds and singing techniques. . E.g:

Sample 4 "Washing Vegetable Heart" (Hunan Flower Drum Minor) Fragment

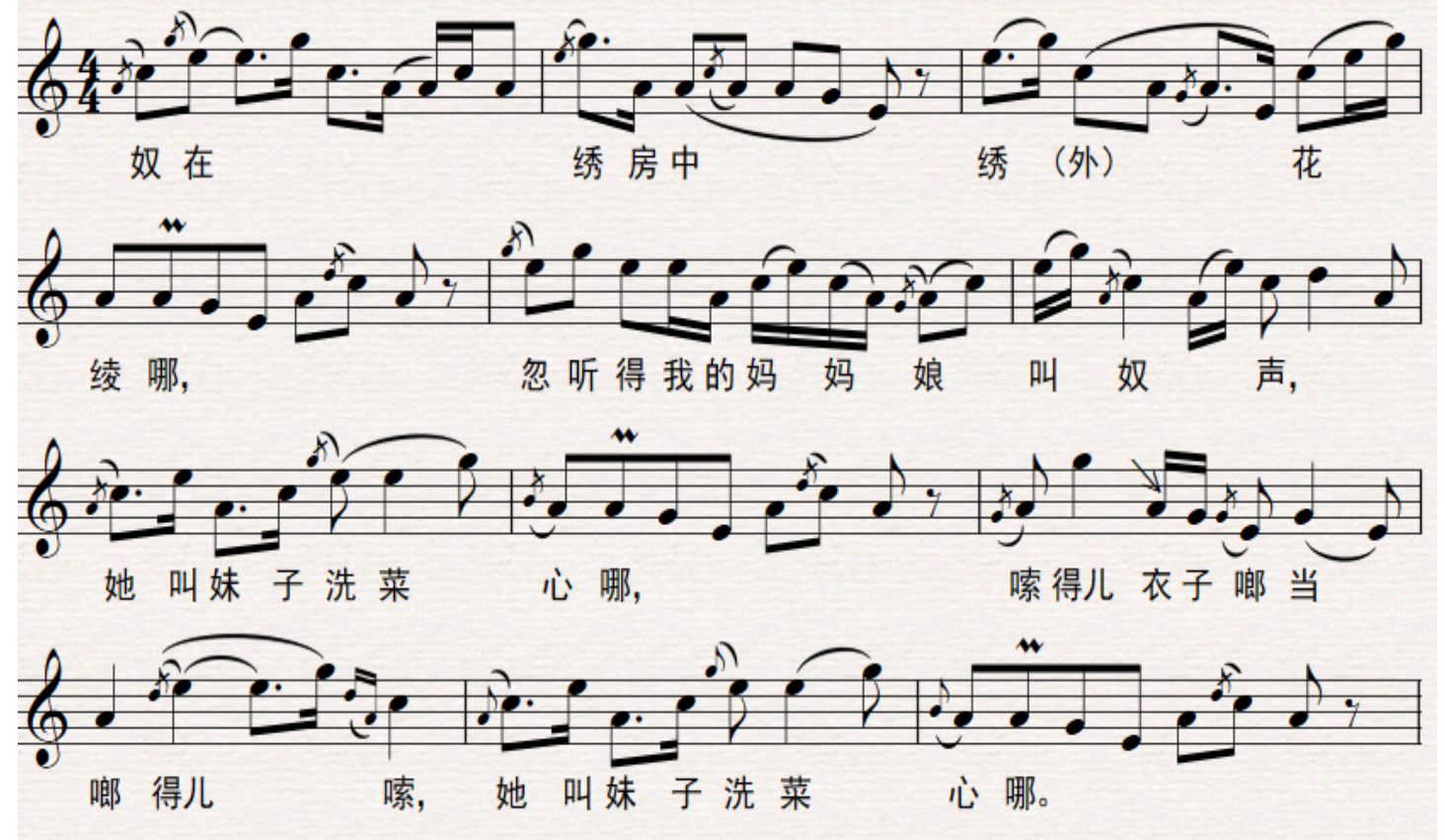

Washing Vegetables is a classic Hunan drum major. It is deeply loved by the masses for its funny and playful style. To sing the song, you must sing in a standard local dialect, and you should pay attention to everything from narration to performance. At the same time, a large number of decorative sounds and singing techniques are used in the song, such as: Boeing, tremolo, flicking the cavity, and playing the tongue. By grasping these singing points, the national charm, ethnic style, and local characteristics of singing are also more vivid.

"Thirteen rhymes" is one of the important methods and methods of singing training in China. It has a clear distinction with foreign singing training. Grasping the theory and training of "Thirteen rhymes” helps us better grasp the bite and spit in national vocal music. The national styles of words, language styles, local characteristics, national charms, and singing skills are also conducive to a better interpretation of vocal music, and ultimately greatly improve the singer's level and ability.

\section{References}

[1] Song Chengxian, Singing and Speaking Training and Thirteen Rhymes, Beijing Central University for Nationalities Press, 1998.

[2] Wang Yingmei, The role of thirteen dragons in singing, Northeast Normal University, 1988.

[3] Yang Li, On "Thirteen Commandments" in Chinese National Vocal Music Performance, Journal of Xinghai Conservatory of Music, No. 3, 2017.

[4] Li Xiaoer: "National Vocal Music Singing Art", Hunan: Hunan Literature and Art Publishing House, 2001. 
[5] Du Qingyun, The application of thirteen dragons in singing skills, Journal of Xingyi Normal University for Nationalities, 2010(4).

[6] Ma Zhikai, The Formation and Practical Value of Drama Thirteen, The Stage, 2009. (1).

[7] Liu Kaihua, On the Experience of Using 13 Artists in Singing Chinese Art Songs, Film Review, 2008.7.

[8] Gao Ge, Discussing Chinese National Vocal Music Singing Styles from the Word-Breaking-words, National Music, 2009. (3).

[9] Huang Zhiyong, On the Singing Style of National Vocal Music, Social Studies, 2007(10).

[10] Wang Yuan, The exploration of Chinese characters in national vocal music singing, Sichuan Theater, 2007(1).

[11] Liu Xueyan, Talking about "Rectangle" and "Sound and Love" in National Vocal Performance, Music World, 2010 (1).

[12] Wang Xin, Reflections on Chinese National Vocal Music Singing Style, Journal of Jiangxi Science \& Technology Normal University, 2009(6) .

[13] Zhao Xiaoxi, The application of singing, articulation, rhyming, and singing in singing, The Life of Literature and Arts, May, 2011 (9).

[14] Liu Yiying, Talking about the wording and rhythm in national singing, Jilin Art Institute, 2010.

[15] Zhao Zhenling, Chinese National Vocal Music Style and Method, Chinese Music, 1997(2).

[16] Xue Qianghua, Thirteen rhymes method of vocal music teaching and national vocal music teaching, Art 100, 2012 (2). 